\title{
O ENSINO DE FÍSICA PARA DEFICIENTES \\ VISUAIS A PARTIR DE UMA PERSPECTIVA \\ FENOMENOLÓGICA
}

\section{The Physics education for visually impaired people from a phenomenological perspective}

\author{
Luciano Gonsalves Costa ${ }^{1}$ \\ Marcos Cesar D anhoni Neves ${ }^{2}$ \\ D ante Augusto Couto Barone ${ }^{3}$
}

Resumo: 0 ensino de Física para pessoas com deficiência visual é investigado a partir da perspectiva do professor de deficientes visuais e dos estudantes deficientes visuais. Professores de deficientes visuais e estudantes com deficiência visual são entrevistados sobre questões inerentes ao estar ensinando ou ao estar aprendendo ciências. 0 resultado da análise das entrevistas serve de subsídio para 0 aperfeiçoamento do atual ensino de física das pessoas com deficiência visual.

Palavras-chave: ensino de Física. deficiência visual. inclusão escolar

Abstract: Physics education for visual impairment is investigated in this paper. Teachers of visually impaired students and visually impaired students were interviewed with questions about the teaching and learning of science. The results reveal elements that need to be onsidered in the physics teaching to visually impaired students.

Keywords: Physics education. visual impairment. inclusion education.

\footnotetext{
1,2 D epartamento de Física; Programa de Pós-G raduação em E ducação para a Ciência e 0 E nsino de M atemática, U niversidade E stadual de M aringá (UE M).E -mail: luciano@ dfi.uem.br; macedane@ yahoo.com

${ }^{3}$ Instituto de Informática; Programa de Pós-G raduação em Informática na E ducação, U niversidade Federal do Rio G rande do Sul (UFRG S). E-mail: barone@ inf.ufrgs.br
} 


\section{Introdução}

O presente trabalho aborda a problemática do ensino de Física para pessoas com deficiência visual ${ }^{4}$, no contexto atual da Educação Inclusiva. Trata-se de uma questão que não foi investigada suficientemente de forma sistemática e detalhada.

Na Pesquisa em Educação em Ciências são praticamente inexistentes os registros sobre 0 ensino dirigido aos portadores de necessidades especiais. As poucas informações existentes dizem respeito a ensaios ou observações isoladas, mas nada que represente uma base de dados estruturada; e isso ocorre tanto com as questões psicológicas, como com as metodológicas ou epistemológicas.

Na literatura especializada, ainda é pequena a quantidade de trabalhos sobre esse tema. Entre esses, a maioria refere-se à instrumentação adaptada a cegos (Baughman e Zollamn, 1977; D elucchi e Malone, 1982; Lennon et al., 1976; Linn, 1972; Sevilla et al., 1991) ou simplesmente divulga os poucos projetos em desenvolvimento na área (Camargo et al., 2000; Santos, 2000).

Indiscutivelmente, esse é um campo em que a pesquisa é incipiente ${ }^{5}$ mas cujas questões merecem um tratamento sistemático aprofundado. Várias interrogações permanecem sem repostas e há um conjunto potencial de questionamentos sobre a aprendizagem escolar, 0 ensino etc., passível de investigação nesse contexto ${ }^{6}$ (Camargo, 2000; Costa, 2004).

\footnotetext{
${ }^{4} \mathrm{O}$ termo deficiência visual está associado a um estado irreversível de diminuição da capacidade visual de um indivíduo, ocasionada por fatores congênitos (patogenias) ou ambientais (patologias, lesões, tumores etc.), e que se mantém mesmo após a sua submissão a procedimentos clínicos (terapias) e/ ou cirúrgicos e o uso de auxílios ópticos convencionais (óculos, lentes de contato). A diminuição da capacidade visual individual varia de leve, moderada, severa, profunda (que compõem o grupo de visão subnormal ou baix a visão) até a ausência completa da visão (ecgueira). No país, de acordo com o D ecreto nº 3.298/ 1999 (Brasil, 2004), que versa sobre a política nacional para a integração da pessoa portadora de deficiência, o indivíduo com baixa visão ou visão subnormal é aquele que apresenta uma acuidade visual menor que 20/ 200 à percepção de luz (isto é, após a correção da visão do melhor de seus olhos, ele vê a menos de 20 metros o que uma pessoa de visão comum pode enxergar a 200 metros), ou um campo visual menor que 20 graus do seu ponto de fixação, mas que usa ou é potencialmente capaz de utilizar a visão no planejamento e/ ou execução de determinadas tarefas.

Há vários tipos de classificação da deficiência visual. Quanto ao grau de intensidade da limitação visual, a deficiência visual é classificada em leve, moderada, severa, profunda e cegueira. De acordo com o nível de comprometimento do campo visual, o comprometimento pode ser central, periférico ou o campo visual não apresenta alteração. Conforme a cronologia da deficiência, ela pode ser congênita ou adquirida. Se ela tem relação com algum outro tipo de deficiência, como a surdez, por exemplo, a deficiência é múltipla.

${ }^{5}$ No campo da Pesquisa em Educação em Ciência, tanto no cenário nacional como no internacional, a presença dessa temática dentre suas linhas é algo relativamente recente. A título de ilustração, somente em 2003 é que se verificou a introdução do tema "Educação e Portadores de Necessidades Especiais (Relações Educativas e portadores de necessidades especiais, Processos de aprendizagem em portadores de necessidades especiais)" na pauta de um dos eventos de grande repercussão dentro da área no país: International Meeting Language, Culture and Cognition (a $2^{\mathrm{a}}$ edição do "Encontro Internacional Linguagem, Cultura e Cognição" foi realizada entre 16 e 18 de julho de 2003, na Universidade Federal de Minas G erais, Belo Horizonte, Minas Gerais).

${ }^{6}$ Apesar disso, ainda há uma carência de projetos que procurem trabalhar amplamente os processos de ensino-aprendizagem, cognição e linguagem relativa à fenomenologia física com deficientes visuais.
} 
Em especial, a indagação fenomenológica " 0 que é isto, 0 ensino de Física para deficientes visuais?" , é uma questão premente, inquiridora e que guarda consigo um universo de situações incompreendidas ou não sabidas.

\section{A investigação}

Entendemos que um estudo sobre o ensino para deficientes visuais deva, necessariamente, envolvê-los e, também, a seus professores.

Acreditamos que ouvindo essas pessoas, e com elas, seja possível identificar algumas das barreiras escolares existentes, para, assim, melhor contextualizá-las e, então, iniciar um caminho alternativo para sua desejada remoção.

Do ponto de vista da pesquisa qualitativa ${ }^{7}$, isso torna as opiniões construídas por estudantes/ professores importantes fontes de dados para um estudo dessa espécie.

Assumiremos, então, que as descrições das experiências vividas no ensinar/ aprender constituem um caminho para a compreensão das coisas do universo escolar dos deficientes visuais, de modo que seus discernimentos possam conduzir a uma inteligibilidade articulada da problemática investigada.

Nesse sentido, adotamos a entrevista como método para a compreensão dessa realidade escolar e professores de deficientes visuais e estudantes com deficiência visual foram convidados a descreverem suas experiências, no magistério com aqueles e de escolarização desses, respectivamente.

Solicitamos que falassem de dificuldades enfrentadas na escola, do preparo do professor, da infra-estrutura presente (livros e outros recursos didáticos, tecnologias etc.), de seus anseios, do que poderia ser imediatamente melhorado (e o que sugeriria!), do que deveria ser mudado, enfim, da situação específica de ensinar/ aprender Ciências.

Não excluímos, portanto, a importância do referencial do educando deficiente visual na orientação do processo de tomada de dados. Logo, uma tentativa mais efetiva de compreensão do fenômeno ${ }^{8}$ "o que é isto, uma educação para as pessoas com deficiência visual?" foi levada adiante.

Nessa busca, tentamos entrevistar o maior número possível desses professores e estudantes do Ensino Médio, na expectativa de que a interpretação do corpo de dados encontrado pudesse trazer elementos que contribuíssem para a composição de um ensino de Física mais adequado às necessidades específicas desses educandos.

Num primeiro momento, o contato entre o pesquisador e os indivíduos da amostra estudada ocorreu de maneira pessoal e informal. Posteriormente, foram enviadas correspondências solicitando que narrassem, em forma escrita, suas vivências escolares.

\footnotetext{
${ }^{7}$ Pesquisa qualitativa é aqui entendida como a pesquisa que considera o caráter subjetivo do conhecimento, sem ligá-lo a relações positivistas de causa-efeito.

${ }^{8} \mathrm{O}$ significado de fenômeno vem da expressão grega fainomenon e deriva-se do verbo fainestai, que quer dizer mostrar-se a si mesmo.
} 
De um universo de cinco estudantes com deficiência visual e dez professores de deficientes visuais identificados na rede escolar, considerados potenciais entrevistados, obtivemos respostas de quatro professores e de três estudantes. Contudo, apesar do pequeno número de entrevistas, conforme perceberemos, o resultado das análises mostra que o material recebido é qualitativamente rico'.

D e cada narração escrita, lida e relida com a atenção necessária, foram extraídos os trechos ("unidades de significado" ${ }^{10}$ ) que podiam revelar elementos para 0 esclarecimento do fenômeno educativo em questão.

A fala de cada entrevistado passou por um processo de redução fenomenológica (D artigues, 1973; Husserl, 1986; Martins, 1988; Martins e Bicudo, 1989; Martins et al., 1990), em que os trechos que comportavam aparentes redundâncias foram excluídos da parte significativa do todo, sobrevivendo as "discriminações" (unidades) significativas, que definiram 0 padrão ideográfico ${ }^{11}$ da fala de cada sujeito. A pós a compreensão de cada padrão ideográfico delineado, nasceu a convergência das falas dos estudantes com deficiência visual e dos professores de deficientes visuais, que aparecerá representada na Tabela 1.

Conforme Neves (1991, p. 32-33) esclarece:

D iz H usserl em sua obra D ie Idee D er Phänomenologie, que a redução é empregada para a atribuição de um índioe zero a todo transcendente (o que não é dado imanentemente). A redução é claridade, a compreensão da possibilidade do aprender, do fazer, do estar, do ser e do vir-a-ser.

Ainda, segundo o autor:

N o processo de redução devemos aos poucos apreender os discursos em suas totalidades, nas contingências que onstroem a teia na qual 0 ser se movimenta. A s contingências vistas não como lacunas. A ntes disso! $\mathrm{V}$ istas como massa que prenche a vida e que, paradox almente, desloca a visualização das essências do viver. (Neves, 1991, p. 33)

Seguem nossas compreensões ideográficas e a compreensão eidética ${ }^{12}$ imediata das falas dos professores e dos estudantes entrevistados.

\footnotetext{
${ }^{9}$ Ao contrário dos estudos quantitativos, não nos ocuparemos da avaliação do grau de representatividade da amostra estatística estudada, mas julgaremos se essa amostra é um significante dentro do contexto investigado (amostra significativa). Portanto, é a ampla contextualização do conjunto de dados que criará a possibilidade de se estabelecer relações significativas entre as informações ou de fazer inferências.

${ }^{10}$ Unidades retiradas das falas que comportam as prováveis essencialidades destas.

${ }^{11} \mathrm{O}$ termo ideográfico tem aqui o sentido de representação de idéias (ideogramas).

${ }^{12}$ Segundo Edmund Husserl, filósofo alemão (1859-1938), relativo à essência das coisas e não à sua existência ou função.
} 


\section{Compreensão ideográfica da fala do professor de deficientes visuais ${ }^{13}$}

\section{Compreensão ideográfica da fala do sujeito PA}

$\mathrm{O}$ discurso do sujeito PA é baseado em anos de docência com alunos portadores de deficiência visual. Segundo essa vivência, os grandes fatores que acarretam problemas de aprendizagem entre esses alunos [e até com alunos não portadores de necessidades especiais] são: salas lotadas, falta de recursos materiais e humanos [professores capacitados para o processo ensino-aprendizagem desses alunos], falta de recursos adaptados, salas de apoio, interesse dos professores, falta de comunicação [Braille - conhecimentos dos professores e bibliografia necessária para a formação].

$O$ professor vê a necessidade de uma sala de apoio, mas com professores capacitados para o ensino de Física, Química e Matemática.

Vê-se que o discurso do professor mantém muitas vezes os termos "cego", "deficientes visuais", "normais" [ao diferenciar os alunos de uma sala comum]. Essa particularidade revela o universo cultural em que está imerso o professor: um universo aberto somente aos alunos sem necessidades especiais. 0 déficit cultural que vitima 0 aluno, muitas vezes vitima também a fala do professor.

\section{Compreensão ideográfica da fala do sujeito PB}

Apesar do pouco tempo [quatro anos] como professor de alunos com necessidades especiais, o sujeito revela a existência de um número diferenciado de professores "treinados" em relação ao Ensino Fundamental e Médio, destacando que nesse último nível não há condições favoráveis para o desenvolvimento do processo ensino-aprendizagem.

Salienta a falta de preparo, de materiais didáticos e tempo para o completamento do processo. Outro fator importante salientado pelo sujeito é a "minimização" do preconceito em relação aos "deficientes físicos". Confessa que os professores não sabem lidar com alunos especiais, o que acaba acarretando um prejuízo pedagógico, um déficit cultural, nos alunos.

\section{Compreensão ideográfica da fala do sujeito PC}

O sujeito salienta que quase inexistem estudos sobre a temática de educação científica para deficientes visuais, especialmente por se tratar de ensino que exige muitas "adaptações", o que torna a temática difícil de ser trabalhada.

Entende que o processo de inclusão escolar do deficiente visual exige melhorar as atuais condições da escola [suporte didático, formação docente, entre outros] e, neste sentido, acrescenta que o despreparo dos professores prejudica o trabalho de adaptação de recursos didáticos.

Em sua vivência no magistério com deficientes visuais, identifica a dificuldade de adaptação de recursos didáticos (gráficos ou desenhos/ figuras, por exemplo), além do desconhecimento do código Braille e do Código Matemático Unificado por parte dos professores, como fatores de impacto negativo no ensino dos deficientes visuais.

\footnotetext{
${ }^{13}$ Os professores entrevistados serão identificados por PA, PB, PC e PD, respectivamente.
} 
Ademais, destaca a importância de associações entre a escola e as instituições de ensino superior para a ampliação do atendimento educativo dos estudantes com deficiência visual, e, frente aos descompassos verificados, reitera que o modelo escolar vigente é incapaz de atender à diversidade existente.

\section{Compreensão ideográfica da fala do sujeito PD}

Entende que as pessoas deficientes visuais têm a mesma capacidade de aprender dos demais educandos, e que o ensino deve se realizar em condições adequadas, haja visto que as necessidades são individuais.

Cita o despreparo dos professores e a falta de recursos didáticos (lupa, luminária, material em Braille, textos ampliados etc.) como as principais barreiras encontradas pelo deficiente visual nas escolas regulares. Contudo, admite um certo descaso em relação à situação desses professores e conclui que o maior obstáculo enfrentado pelas pessoas com deficiência visual é a falta de preparo da própria escola para acolhê-los. Sugere, ainda, que com apoio especializado é possível atenuar o impacto negativo das barreiras didáticas sobre o processo educativo desses estudantes.

\section{Compreensão ideográfica da fala do estudante deficiente visual ${ }^{14}$}

\section{Compreensão ideográfica da fala do sujeito EA}

Salienta que a questão do ensino de Física para pessoas com deficiência visual é pouco explorada no campo da pesquisa em ensino de Física. Considera um grande equívoco 0 uso de um modelo de ensino de Física fortemente ancorado no sentido da visão para deficientes visuais e acrescenta que o desconhecimento do código Braille por parte do estudante interfere no prosseguimento de seus estudos e contribui para a evasão escolar. Reitera a necessidade de um pluralismo de abordagens de ensino para conter 0 avanço desse processo de evasão.

Reconhece a importância do apoio dado pelos ledores ${ }^{15}$ aos estudantes não-visuais e acredita que mediante relacionamento recíproco seja possível desfazer alguns dos preconceitos com relação à capacidade dos deficientes visuais.

\section{Compreensão ideográfica da fala do sujeito EB}

Identifica a ininteligibilidade como uma barreira permanentemente encontrada no ensino da Matemática para deficientes visuais, dos estágios iniciais de sua escolarização ao Ensino Médio. Sugere a necessidade de atendimento especializado para a progressão escolar do estudante com deficiência visual e destaca a dificuldade enfrentada por esse estudante para acompanhar disciplinas como Física, Química, Matemática e Biologia dentro da sala comum. Reitera a significância do papel desempenhado pelos ledores na educação das pessoas com

\footnotetext{
${ }^{14}$ Os estudantes entrevistados serão identificados por EA, EB e EC, respectivamente.

${ }^{15}$ Termo técnico usado para indicar as pessoas que lêem (voluntariamente) para um cego.
} 
deficiência visual e aponta a ampliação do preparo do professor como condição para a prática de um ensino inclusivo.

\section{Compreensão ideográfica da fala do sujeito EC}

Identifica "preconceitos" e o despreparo docente com relação ao atendimento de deficientes visuais como barreiras no ensino para pessoas com deficiência visual, inclusive ilustra sua percepção com a frase comumente usada pelo professor quando da organização de passeios com infantes escolares: "V ou deix ar esta [aluna] aqui com vocês pois a mesma é ocya e não poderá participar das brincadeiras om os [ooleguinhas]".

Sugere que a inclusão escolar e 0 atendimento especializado têm impacto positivo na progressão escolar do deficiente visual e reconhece que a assistência prestada por ledores possa diminuir a incompreensibilidade verificada por esses estudantes no estudo de conteúdos de Ciências naturais e da Matemática. Considera um equívoco o uso de uma estrutura visual no ensino para deficientes visuais.

\section{As convergências das falas e a compreensão eidética imediata das situações relatadas pelos sete sujeitos entrevistados}

As convergências denotam, em sua essência fundamental, a convivência do professor de deficientes visuais e de estudantes com deficiência visual com uma realidade que simplesmente não vê o sujeito com deficiência na visão, e, portanto, o exclui. Isso é um indicativo do alto grau de incompreensão que a estrutura educacional existente tem em relação aos portadores de necessidades especiais.

Em última análise, da mesma forma que ocorre no ensino dos videntes, a ausência da experimentação, a matematização excessiva, a carência de recursos adequados, o despreparo docente, a evasão escolar, entre outros, são fatores que tendem a prejudicar o cumprimento dos propósitos da educação em Ciências.

\section{À guisa de conclusão}

O ensino de Ciências naturais para pessoas com deficiência visual está marcado por uma série de contingências que compromete a inclusão do estudante deficiente visual na escola regular, e, outrossim, o exclui do horizonte de possibilidades da educação em Ciência, especialmente em um de seus componentes curriculares: a Física.

A falta de recursos didáticos adequados, a exclusão tecnológica, a ausência da experimentação na escolarização do deficiente visual, a didática baseada exclusivamente no visual, a evasão escolar, o despreparo docente para 0 ensino dos deficientes visuais, a escassez de pesquisas sobre 0 ensino de Física e das Ciências em geral para pessoas com deficiência visual são fatores que concorrem para a manutenção da situação atual dessa modalidade de ensino. Todos esses fatores ajudam a reduzir consideravelmente a possibilidade de promoção/ aperfeiçoamento do entendimento da Ciência na escola. 
Costa, L. G. et al.

Tabela 1

Categorias de convergência das falas dos professores e dos estudantes entrevistados.

\section{CONVERGÊNCIA}

Dificuldade com conteúdos da Matemática e das Ciências Naturais

Falta de recursos didáticos adaptados

Dependência de ledores

Formação insuficiente do professor de Ciências e Matemática para o ensino dos deficientes visuais

Ausência de exploração da percepção tátil e da experimentação no ensino dos estudantes com deficiência visua

Necessidade de ampliação do atendimento educativo para o deficiente visual (apoio especializado, sala de recursos etc.)

Formação insuficiente do professor especializado para o ensino de ciências e matemática para pessoas com deficiência visual

Despreparo do sistema de ensino para promover a inclusão escolar

Existência de preconceitos com relação às pessoas com necessidades especiais

\section{Evasão escolar}

Ausência de pesquisas sobre o Ensino de Física para pessoas com deficiência visual

Predominância de estruturas verbovisuais no ensino dos deficientes visuais

\section{EXCERTOS DE UNIDADES DE SIGNIFICADO CONVERGENTES}

"Ao iniciar o Ensino Médio tive muitas dificuldades nas matérias de exatas. Meu professor de [Matemática] [...] não conseguia ensinar-me devido à sua inexperiência com alunos deficientes visuais"

"faltam ainda nas escolas recursos adaptados"

"[alunos] ligados aos ledores"

"falta de preparo do professor convencional de Física, Química e Matemática para ensinar o deficiente visual"; "a verdade é que, nós professores [...] não sabemos lidar com esses alunos especiais"

"o professor acaba achando que essas [aulas experimentais] não são interessantes para o aluno DV [deficiente visual]"; "pensar em atividades de ensino de Física que façam com que os alunos aproveitem todas as suas percepções, não nos esqueçamos que o vidente também é ouvinte e possui a percepção tátil. [...] uma prática educativa centrada não apenas na visão"

"no terceiro grau [ano] [...] assistências de outras amigas [...]. Uma me dava assistência na sala [e a] outra me dava assistência às tardes na Física, Química, Matemática, Biologia, que era muito difícil de acompanhar [...] dentro da sala de aula junto com os demais alunos"

"Como os professores especializados não têm formação nas áreas específicas [...] fica difícil, muitas vezes, ajudar o aluno no reforço dos conteúdos e até na adaptação dos materiais"

"A inclusão de deficientes visuais no Ensino regular implica reestruturações e adaptações nas atuais condições, de forma que possa adequar as exigências e diversidades necessárias a esta clientela"; "Hoje é o aluno que tem que se adaptar ao sistema já posto, um sistema que [...] nem está dando conta de atender as diversidades já existentes"; "a barreira maior, está na própria escola"

"minimizar o preconceito das pessoas identificadas como "normais" para com os deficientes físicos"; "essa associação da falta da visão à incapacidade de se aprender determinados conteúdos, algo muito interessante. [...] passei por isto na época da graduação, meus colegas combinaram [...] para me ajudar nos estudos. [...] comecei a me sair muito bem nas provas [...] [aí] a coisa mudou, eles começaram a brigar para estudar comigo, já que na verdade, eu é quem os ajudava"

"o que [...] acabava acontecendo é que o aluno ou demorava muito para conseguir avançar nos conteúdos ou muitas vezes a única alternativa era a desistência"

"pequena quantidade de trabalhos [na] área [de ensino de física para DVs]"

"estrutura educacional atual [...] foi pensada para atender [a] alunos videntes. Quase tudo [...] depende do uso da visão. [...] uso da lousa [...] a não percepção pelo aluno do fenômeno [...] necessidade do uso do caderno [...] inviabilizam o ensino de física para dvs" 
D e modo geral, em quaisquer tipos de escola ou níveis de ensino faltam ao deficiente visual a literatura e os recursos didáticos adaptados, computadores e tecnologia específica, monitoria especial, acessibilidade arquitetônica, professores habilitados, entre outros. Isso sem considerar o fato de que a dificuldade torna-se ainda maior à medida em que o grau de escolarização aumenta, impossibilitando o estudante com deficiência visual de concluir, até mesmo, as etapas de escolarização anteriores ao ingresso na universidade: os ensinos Fundamental e Médio. 0 sistema escolar é incapaz de lidar com a deficiência: suas deficiências são bem maiores que as dos assim rotulados "deficientes"!

Nessas circunstâncias, o estudante invisual ${ }^{16}$ continua privado das condições de ensino que melhor correspondem às necessidades impostas pela deficiência visual.

Ainda, as estatísticas oficiais apontam outros índices da exclusão das pessoas com deficiência visual. $\mathrm{Na}$ "era da inclusão", o deficiente visual continua muito excluído, tanto do ponto de vista educacional como tecnológico, trabalhista etc.

D e certa maneira, esse quadro tem uma correlação forte com as representações socialmente construídas e difundidas a respeito das pessoas cegas, mesmo em tempos de grande disponibilidade de informação ("sociedade da informação").

A incompreensão do impacto da deficiência visual sobre o educando faz com que a escola desconsidere seu próprio referencial perceptual no ato da educação. Paradoxalmente, a estrutura concebida para a educação dos videntes (um modelo fundado na crença da superioridade da visão) foi transposta à educação dos não videntes.

A escola definitivamente não é um horizonte de possibilidades para os deficientes visuais, um mundo que se insere no universo das potencialidades do ser humano.

$\mathrm{O}$ desenvolvimento das capacidades humanas, delimitadas por uma realidade contingencial que obstrui sua promoção, urge esforços na busca de ampliação da visão desse mundo no qual o invisual está inserido para poder incluí-lo. Inclusão essa que requer a quebra dos vários impedimentos, mas que não ocorre com a práxis dos mecanismos existentes: um processo de exclusão sistemática.

A compreensão efetiva do "percepcionar" esse mundo em suas contingências revela um caminho para essa inclusão, a saber: a possibilidade de um ensino experimental válido para uma pluralidade de pessoas, videntes e não videntes, e, mesmo assim, essa é apenas a "ponta de um enorme iceberg".

Importante ressaltar que não basta o provimento da escola de meios para a prática do ensino inclusivista, a capacitação docente não pode estar dissociada do processo. Afinal, se 0 professor não é incluído, como pode auxiliar a promover a inclusão?

Pela reflexão, o mundo das possibilidades pode edificar-se novamente.

O horizonte inicial compreendido nos conduziu a um processo de formulação de alternativas experimentais para o ensino de Física para deficientes visuais, que, além de incluir o sujeito invisual, também inclua 0 visual (Costa, 2004.).

${ }^{16}$ Termo utilizado para designar os deficientes visuais. 
Os contrastes verificados no atendimento educativo dos não visuais há muito se fazem presentes na educação dos visuais. As semelhanças são muitas: a qualidade do ensino é questionável, os resultados de aprendizagem são insatisfatórios, a evasão escolar é elevada e as contingências parecem se estender ao infinito. Ambos são vítimas de um sistema que efetivamente não é eficiente na missão de educar.

O uvir aqueles que não vêem, não ouvem, não caminham nos levou a mergulhar no mesmo universo dos que vêem, ouvem, caminham. A exclusão está mais além, complexa. Ela é um caminho de mão dupla e se arquiteta numa pluralidade de inclusão que resta ainda ser construída ...

\section{Referências}

BAUG HMAN JR., J.; ZOLLMAN, D. Physics lab for blind. The Physics Teacher, v. 15, $\mathrm{n}$. 6, p. 339-342, 1977.

BRASIL. Decreto no ${ }^{0}$. 3.298, de 20 de dezembro de 1999. 2004. Disponível em: <http:/ / www.cedipod.org.br>.

CAMARG O, E. P. Um estudo das concepções alternativas de repouso e movimento de pessoas cegas. Bauru. 2000. 219p. Dissertação (Mestrado em Ensino de Ciências) - Faculdade de Ciências, Universidade Estadual Paulista.

CAMARG O, E. P.; SCALVI, L. V. A.; BRAG A, T. M. S. Conceitos sobre repouso e movimento do deficiente visual e modelos históricos. In: ENCONTRO DE PESQ UISA EM ENSINO DE FÍSICA, 7., 2000, Florianópolis. Anais... São Paulo: Sociedade Brasileira de Física. p. 126.

CO STA, L.G . Apropriação tecnológica e ensino: as tecnologias de informação e comunicação e o ensino de física para pessoas com deficiência visual. Porto Alegre. 2004. Tese (D outorado em Informática na Educação) - Programa de Pós-Graduação em Informática na Educação, Universidade Federal do Rio G rande do Sul.

DARTIGUES, A. 0 que é a fenomenologia? Rio de Janeiro: Eldorado, 1973.

DeLUCCHI, L.; MALONE, L. Science activities for visually impaired. In: MANG OLD, S. (O rg.) A teacher's guide to the special education needs of blind and visually handicapped children. New York: American Foundation for the Blind, 1982.

HUSSERL, E. A idéia da fenomenologia. Lisboa: Edições 70, 1986.

LENNO N, E.M.; FEIRER, J.L.; PURDY, W.K. Metrics for visually impaired persons. New Outlook for the Blind, v. 70, n. 1, p. 1-4, jan. 1976. 
LINN, M.C. An experimental science curriculum for the visually impaired. Exceptional Children, v. 39, p. 37-43, 1972.

MARTINS, J. A modalidade fenomenológica de conduzir pesquisa em psicologia. Faculdade de Educação, Universidade Estadual de Campinas, 1988. Notas.

MARTINS, J.; BICUD 0, M. A. V. A pesquisa qualitativa em Psicologia. São Paulo: Moraes, 1989.

MARTINS, J.; BOEMER, M.R.; FERRAZ, C. A A fenomenologia como alternativa metodológica para pesquisa. Cad. Soc. Est. Pesq. Qual., v. 1, n. 1, p. 37-38, 1990.

NEVES, M. C. D. Uma perspectiva fenomenológica para o professor em sua expressão do: "o que é isto, a ciência?". Campinas. 1991. Tese (D outorado em Educação) - Faculdade de Educação, Universidade Estadual de Campinas.

SANTOS, L. T. O olhar do deficiente visual para o ensino de física. In: ENCONTRO DE PESQUISA EM ENSINO D E FÍSICA, 7., 2000, Florianópolis. Anais... São Paulo: Sociedade Brasileira de Física. p. 113.

SEVILLA, J. et al. Physics for blind students: a lecture on equilibrium. Physics Education, v. 26, p. 227-230, 1991. 
